\title{
The Mythology of Feedback
}

\author{
Andy Adcroft \\ Centre for Educational and Academic Development, University of Surrey, Guildford, \\ $U K$
}

(Received XX Month Year; final version received XX Month Year)

\begin{abstract}
Much of the general education and discipline specific literature on feedback suggests that it is a central and important element of student learning. This paper examines feedback from a social process perspective and suggests that feedback is best understood through an analysis of the interactions between academics and students. The paper argues that these two groups will have their own mythology of feedback and that this will inform their beliefs, attitudes and behaviours in the feedback process. Where there are different mythologies, the outcome will be dissonance. The paper reports on a study in which a 15 item questionnaire was distributed to academics and students in a School of Law and a School of Management. 91 responses were received from academics and 1197 from students. The data suggests that academics and students have different perceptions of feedback and this creates dissonance as the two groups offer different interpretations of the same feedback events.
\end{abstract}

Keywords: feedback, feedback, mythologies, social processes, student perceptions, staff perceptions

\section{Introduction}

In discussing the broad purpose of feedback, Mutch (2003) offers a definition that focuses on feedback as a key mechanism in "the development and enhancement of learning" (p.36). This is common across much of the literature. For example, in a study of over 2000 students, Carless (2006) identified feedback as a "key characteristic of quality teaching" (p.219) and suggested that it fulfils a wider variety of functions including the justification of grades given, the demonstration of tutor authority and as a general academic ritual. Bailey (2008) suggests that most of it falls into one or more of a number of different categories which include understanding assessment criteria, experiences of feedback and the language used in feedback. The majority of research into feedback, therefore, approaches the subject matter from a technical process perspective. This paper considers feedback from a social process perspective. The first section provides some theoretical underpinning by discussing the nature of social processes and the central role played by mythologies before 
establishing the most common mythology of feedback. The next section explains the approach taken to the gathering of data before moving onto the presentation of the findings of the primary research. The final section discusses some of the implications of the study before making suggestions for further research in the area.

\section{Theoretical Underpinning}

The notion of feedback as a social process, where the fundamental points of analysis are the human relationships involved, stands in stark contrast to much of the literature on feedback which views it as a technical process where the focus is on the activities rather than the actors involved. The outcome of this is a body of literature which emphasises areas such as "learning outcomes, assessment tasks, assessment criteria and marking procedures" (Case, 2007, p.287), the characteristics of feedback (Vardi, 2009), forms of feedback (Orrell, 2006 and Hyatt, 2005) and the frequently disappointing outcomes of feedback (Gibbs and Simpson, 2004-5). The limitation of this approach is that it paints an incomplete picture as it frequently fails to address the a priori assumptions which underpin the behaviour of both academics and students. For example, Parry (1998) promotes the analysis of social processes as it gives a better understanding of the "values, beliefs, attitudes and motivations" (p.86) which underpin behaviours and, hence, outcomes. Similarly, Sampson et al (2002) argue that social processes are much more important than, for example, technical or economic processes in understanding well-being within any collective group.

For Eden (1992) social processes involving “interaction and engagement between people" (p.799) are driven by two factors. The first is the "social construction of reality" (p.800) that each participant engages in which provides the basis on which their own actions and the actions of others are judged and assessed. The second factor is an individual's "negotiation and management of meaning" 
(p.800) whereby they try to make sense of what is happening to and around them.

Maitlis (2005) describes this social process as sensemaking and it involves individuals utilising their own theories, assumptions and experiences in order to "construct accounts that allow them to comprehend the world and act" (p.21). The idea that individuals take a bundle of preconceptions into any set of circumstances, and that these preconceptions form a starting point for their understanding, is developed further by Macdonald et al (2006) who develop the concept of mythologies. In this context, mythologies are defined as a set of underlying assumptions and beliefs that determine interpretation and behaviour. A mythology operates both consciously and unconsciously and whilst it may not be factually correct it contains a "fundamental truth" (Macdonald, 2006, p.18). Mythologies matter because, where they are shared, they form the basis of cultures which further reinforce assumptions, theories and accepted wisdom.

Zydziunaite and Lepaite (2009) suggest that the entrenchment of mythologies into cultures is the most significant element of perceptions and behaviours. Macdonald et al (2006) use the concept of dissonance to explain how these different models of behaviour can impact on organisations. They suggest that dissonance is present when a culture's expectations or assumptions are challenged. In this study, for example, what happens when students receive feedback in an unexpected form or when students act on feedback in an unexpected manner? For Espeland and Stevens (1998) this should trigger the social process of commensuration whereby common ground is found between different groups who offer different interpretations and understandings of the same phenomenon. This notion of common ground is fairly typical in many social process approaches; Maitliss (2005), for example, identifies the 
dissonance between different mythological cultures as being "surprising or confusing" (p.21) for those involved and argues that this is a necessary step in moving towards a common understanding and outcome. What should not be underestimated, therefore, is "the importance of understanding other mythological lenses" (Macdonald, 2006, p.28).

The starting point for this paper's analysis of feedback is the assumption that feedback is central and crucial to learning, an assumption which is supported by much of the generalist education literature as well as the more discipline specific literature. Orrell (2006), for example, suggests that feedback is the "cornerstone of all learning" (p.441) and in the same way Mutch (2003) argues that feedback is the key mechanism in "the development and enhancement of learning" (p.36). Given this importance of feedback, it is unsurprising to see a consensus across the literature. Hounsell et al (2006) say, for example, that the link between feedback and learning has "long been acknowledged" (p.1), Woolf (2004) identified "widespread agreement" (p.479) on this issue and Weaver (2006) notes that, across the generalist literature at least, the assumption is "accepted in academic circles" (p.379). For Crisp (2007) the increasingly uncritical acceptance of this assumption, as the a priori for both research and practice, explains why ever more time and effort is spent across higher education on improving the quality of feedback to students.

Bone (1999) identifies disciplines such as science, engineering, geography and medicine where there is both a substantial body of literature and a consensus on feedback. Race (2007), for example, discusses it in the context of Physical Sciences education and concludes that "feedback is the oil which lubricates the cogs of 
learning" (p.47) and this is common across many other disciplines such as Business and Management where is it viewed as one of "the most powerful components" of student learning (Handley et al, 2009, p.3), the Built Environment where it is "essential" to student learning (Cowan, 2004, p.1) and Economics where it is viewed as "exceptionally useful" to learning (Miller, 2004, p.18). Feedback, therefore, plays a crucial role in the specific requirements of different disciplines. As examples, Moriarty and Rajapillai (2009) suggest that, in English, feedback makes the most important contribution to student writing skills and critical abilities and Holmes and Papageorgiou (2009) suggest that it is a crucial element in how students of Tourism "learn how to improve" their subject specific skills, an element which is "well established" in the tourism education literature (p.86). There is also a more instrumental dimension to feedback where, for example, Glover (2004) argues that it is crucial to student progression and retention in Science Education (p.3).

This assumption of the importance of feedback is primarily built on the relationship between feedback and performance; high quality feedback can be used to improve performance. Bloxham and West (2007), for example, discuss feedback as the primary mechanism through which students improve over time and Holmes and Papageorgiou (2009) identify many studies which place feedback at the core of improvements to understanding. These studies tend to focus on three issues. First, the role feedback plays in explaining what good performance is; Miller (2009), for example, suggests that high quality feedback clarifies what is expected of students and Holmes and Papageorgiou (2009) argue that it creates an understanding which is "shared by both students and tutors" (p.87). Second, feedback plays a diagnostic role (Handley et al, 2009) which is crucial in identifying gaps in knowledge and 
understanding; Nicol and MacFarlane-Dick (2006), for example, suggest that this should be the main outcome of any feedback activity. Finally, performance is improved through feedback because it facilitates the development of study skills; Barrow (2006) argues that through feedback "students are encouraged to adjust their approach" (p.358) and, again, this is a common assumption across many disciplines such as the Physical Sciences (Race, 2007, p.9), Medical Education (Parikh et al, 2001, p.632) and Legal Education (Bone, 2006, p.1).

The broad outcome of all this is that feedback is a mechanism for changing the behaviour of students as they learn and this should, therefore, have an impact on their ability to fulfil their own potential and meet their own objectives. Hyland and Hyland (2001) discuss this in the context of student diversity and point out that different students will have different aspirations and motivations and, therefore, will want different things from feedback. Common to all these different elements, however, is the notion that feedback should create a "stimulating learning environment" (Koka and Hein, 2003, p.333) which will serve to motivate students in both their present and future performance (Weaver, 2006). One of the main behavioural changes that feedback should foster is independent learning whereby students become adept at self-reflection and self-development; Bone (1999) argues that this should occur provided that feedback is prompt, encouraging, constructive and rational.

If a mythology is constructed by what we think about something and the reasons why we think that, dissonance will occur if different cultures have significantly different mythologies. For example, do academics and students share the belief that feedback is crucial to a learning experience because it contributes to 
improved performance and behavioural change? Where there is dissonance, broadly speaking, the literature suggests two possible causes. The first of these is poor practice. Vardi (2009), for example, argues that it is often the result of poor practice whereby feedback is too brief, not specific enough, involves arbitrary judgements about standards and uses terms which may be vague, cryptic, sarcastic and lacking in praise. Burke (2009) also suggests that poor practice is the primary cause of poor outcomes: "it is too brief, too negative, too difficult to decipher or to understand" (p.42). The second explanation, and the one that this study addresses, is that there is a gap in understanding and expectations of feedback between academics and students. Parikh et al's (2001) work, for example, concluded by suggesting that "faculty members perceive that they provide effective feedback more often than students perceive that they receive such feedback" (p.632). The main manifestation of this gap is the body of evidence which suggests that students do not understand the content and purpose of feedback: Crisp (2007) points out that what may be "self evident" to academics is often not to students (p.574); Orrell (2006) raises issues of the "expert language of academic disciplines" (p.441); Hyatt (2005) argues that the "rhetorical conventions" of feedback are frequently confusing to students (p.340); Williams (2005) suggests that academic language is "opaque to many university students" (p.168) and Weaver's (2006) evidence suggests that students do not have a significant understanding of academic discourse in order to make best use of feedback. We now turn to discuss the empirical investigation of the mythology of feedback.

\section{Approach}

This study aims to answer two related research questions. The first question is: Do academics and students share the same feedback mythology? For the purposes of this study, and building on the work of Macdonald et al (2006), a mythology is viewed as 
having two components; what is believed and the reasons why it is believed. The second question is: If there is only a limited sharing of feedback mythology, how does the dissonance this creates manifest itself? Conceptually, there are two ways in which these questions can be addressed. The first way is to establish the nature of the feedback mythology within the two different groups and the second way is to compare both groups against an already established perception of feedback. Given the consensus in both the generalist education and discipline specific literature about feedback discussed earlier, the second of these options has been chosen and so the perception of feedback against which the two groups will be measured is that feedback is a crucial element which enriches the student learning experience because it is important in improving performance and changing learning behaviour. The possibility of dissonance between the two groups is assessed across a number of different feedback events and activities that focus on three areas. The first area is the frequency of feedback and how often academics feel they give and students feel they receive feedback. The second area is the form of feedback and whether there is a common understanding between academics and students about written and nonwritten feedback. The final area is assessed work and the elements of feedback which are important in this. Figure 1 below shows the conceptual model underpinning this study. 
Figure 1: A conceptual model of the relationship between feedback mythology and dissonance

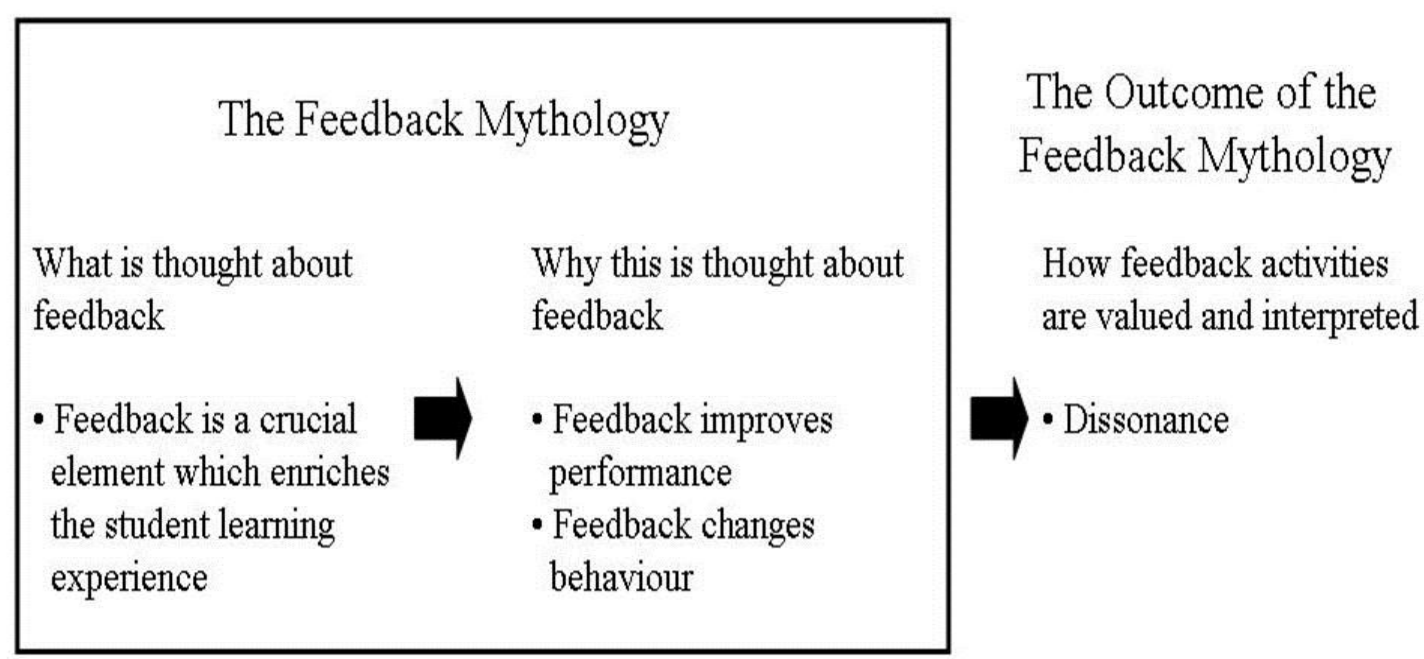

On the basis of this model, a 15 item questionnaire was developed in three sections. The first section, containing just one question, concerned the importance of feedback to the student learning experience. The second section concerned why feedback was perceived as being important and contained 8 questions about performance and behaviour. The final section concerned dissonance and asked six questions about the frequency, form and assessment base of feedback. Given the differences in the two groups, questions were worded slightly differently for academics and students. Each question was worded as a statement and academics and students were asked to respond on a 5 point Likert Scale which ranged from 'Strongly Disagree' to 'Strongly Agree'. In order to maintain consistency across the questionnaire, the term "feedback" was used rather than alternatives such as words like "guidance", "advice" and "support". Whilst this does, to an extent, assume a common understanding of the term "feedback", it was done for three reasons. First, in using common words throughout it would be easier to identify where the differences in perception are between staff and students. Second, feedback is the most common word used amongst academics and students in the faculty which formed the basis of 
this study for the activities under discussion. Finally, in the theoretical grounding of the questionnaire the most commonly used term was "feedback" and so in replicating this comparisons across different studies may be easier and more valid.

Table 1 below presents the questions and from where in the relevant literature they were drawn. 
Table 1. Questionnaire items

\begin{tabular}{|c|c|c|c|}
\hline Students & Staff & Measuring & Source \\
\hline \multicolumn{4}{|c|}{ What is believed about feedback } \\
\hline $\begin{array}{l}\text { Feedback is a crucial element of } \\
\text { my whole learning experience }\end{array}$ & $\begin{array}{l}\text { Feedback is a crucial element of } \\
\text { the whole student learning } \\
\text { experience }\end{array}$ & Importance & $\begin{array}{l}\text { Orrell (2006) } \\
\text { Mutch (2003) } \\
\text { Hounsell et al (2006) } \\
\text { Woolf (2004) } \\
\text { Weaver (2006) } \\
\text { Crisp (2007) } \\
\end{array}$ \\
\hline \multicolumn{4}{|c|}{ Why it is believed about feedback } \\
\hline $\begin{array}{l}\text { Feedback plays a crucial role in } \\
\text { improving my performance }\end{array}$ & $\begin{array}{l}\text { Feedback is the main mechanism } \\
\text { through which a student's } \\
\text { performance is improved }\end{array}$ & Performance & $\begin{array}{l}\text { Bloxham and West } \\
\text { (2007) } \\
\text { Holmes and } \\
\text { Papageorgiou (2009) }\end{array}$ \\
\hline $\begin{array}{l}\text { Feedback is important because it } \\
\text { clarifies for me what good } \\
\text { performance is through the } \\
\text { establishment of criteria and } \\
\text { expected standards }\end{array}$ & $\begin{array}{l}\text { Feedback clarifies what good } \\
\text { performance is through the } \\
\text { establishment of criteria and } \\
\text { expected standards }\end{array}$ & Performance & $\begin{array}{l}\text { Miller (2009) } \\
\text { Holmes and } \\
\text { Papageorgiou (2009) }\end{array}$ \\
\hline $\begin{array}{l}\text { Feedback explains to me the } \\
\text { gaps in my knowledge and } \\
\text { understanding }\end{array}$ & $\begin{array}{l}\text { Feedback explains to students the } \\
\text { gaps in their knowledge and } \\
\text { understanding }\end{array}$ & Performance & $\begin{array}{l}\text { Gibbs and Simpson, } \\
2004-5 \\
\text { Nicol and MacFarlane- } \\
\text { Dick, } 2006\end{array}$ \\
\hline $\begin{array}{l}\text { The feedback I receive directs } \\
\text { me towards the most appropriate } \\
\text { study practices }\end{array}$ & $\begin{array}{l}\text { Feedback directs students towards } \\
\text { the most appropriate study } \\
\text { practices }\end{array}$ & Performance & $\begin{array}{l}\text { Barrow (2006) } \\
\text { Race (2007) }\end{array}$ \\
\hline $\begin{array}{l}\text { The feedback I have received has } \\
\text { helped to identify the gap } \\
\text { between my current and hope for } \\
\text { performance }\end{array}$ & $\begin{array}{l}\text { Feedback identifies the gap } \\
\text { between a student's current and } \\
\text { hoped for performance }\end{array}$ & Performance & $\begin{array}{l}\text { Gibbs and Simpson, } \\
2004-5 \\
\text { Nicol and MacFarlane- } \\
\text { Dick, } 2006\end{array}$ \\
\hline $\begin{array}{l}\text { As a result of the feedback I } \\
\text { receive, I can accurately self- } \\
\text { assess and self-correct my } \\
\text { performance }\end{array}$ & $\begin{array}{l}\text { Feedback enables students to } \\
\text { accurately self-assess and self- } \\
\text { correct their own performance }\end{array}$ & Behaviour & $\begin{array}{l}\text { Miller, } 2009 \\
\text { Barrow, } 2006\end{array}$ \\
\hline $\begin{array}{l}\text { The feedback I receive is a } \\
\text { mechanism for self-reflection } \\
\text { and self-development }\end{array}$ & $\begin{array}{l}\text { Feedback is a mechanism for self- } \\
\text { reflection and self-development }\end{array}$ & Behaviour & $\begin{array}{l}\text { Miller, } 2009 \\
\text { Barrow, } 2006\end{array}$ \\
\hline $\begin{array}{l}\text { I am motivated and encouraged } \\
\text { in my studies as a result of the } \\
\text { feedback I receive }\end{array}$ & $\begin{array}{l}\text { Feedback encourages and } \\
\text { motivates students in their studies }\end{array}$ & Behaviour & $\begin{array}{l}\text { Miller, } 2009 \\
\text { Koka and Hein, } 2003\end{array}$ \\
\hline \multicolumn{4}{|l|}{ Dissonance } \\
\hline $\begin{array}{l}\text { I receive frequent feedback } \\
\text { during a module, not just on my } \\
\text { assignments and other assessed } \\
\text { work }\end{array}$ & $\begin{array}{l}\text { Students receive frequent } \\
\text { feedback during a module, not } \\
\text { just on assignments }\end{array}$ & Frequency & $\begin{array}{l}\text { Mutch, } 2003 \\
\text { Burke, } 2009\end{array}$ \\
\hline $\begin{array}{l}\text { I get feedback on how I am } \\
\text { doing nearly every time I meet } \\
\text { with a lecturer to discuss an } \\
\text { academic issue }\end{array}$ & $\begin{array}{l}\text { Feedback occurs nearly every } \\
\text { time a student meets with a } \\
\text { lecturer to discuss an academic } \\
\text { issue }\end{array}$ & Frequency & $\begin{array}{l}\text { Williams, } 2005 \\
\text { Hyatt, } 2005\end{array}$ \\
\hline $\begin{array}{l}\text { I have received feedback which } \\
\text { takes a variety of written and } \\
\text { non-written forms }\end{array}$ & $\begin{array}{l}\text { Feedback takes a variety of } \\
\text { written and non-written forms }\end{array}$ & Form & $\begin{array}{l}\text { Vardi, } 2009 \\
\text { Williams, } 2005\end{array}$ \\
\hline $\begin{array}{l}\text { Verbal feedback now and then is } \\
\text { a really useful supplement to } \\
\text { written feedback }\end{array}$ & $\begin{array}{l}\text { Periodic verbal feedback is a } \\
\text { necessary supplement to written } \\
\text { feedback }\end{array}$ & Form & $\begin{array}{l}\text { Gibbs and Simpson, } \\
2004-5 \\
\text { Hounsell et al, } 2006 \\
\end{array}$ \\
\hline $\begin{array}{l}\text { The most important feedback } \\
\text { that I receive is the mark on a } \\
\text { piece of work or examination }\end{array}$ & $\begin{array}{l}\text { The most important feedback that } \\
\text { students receive is their mark }\end{array}$ & Assessment & $\begin{array}{l}\text { Hyland and Hyland, } \\
2007 \\
\text { Case, } 2007\end{array}$ \\
\hline $\begin{array}{l}\text { The most useful feedback I get is } \\
\text { written feedback on my } \\
\text { assignments }\end{array}$ & $\begin{array}{l}\text { The most useful feedback that } \\
\text { students receive is written } \\
\text { feedback on assignments }\end{array}$ & Assessment & $\begin{array}{l}\text { Carless, } 2006 \\
\text { Crisp, } 2007\end{array}$ \\
\hline
\end{tabular}


The sample for this study was drawn from a single Faculty in a research led university in the UK. The Faculty is made up of two schools, Law (SoL) and Management (SoM) and, in terms of both students and academics, SoL is significantly smaller than SoM. SoL is primarily an undergraduate school with over $95 \%$ of its students studying at this level, the vast majority of which study on an LLB degree. SoM, by way of contrast, has a large postgraduate intake which accounts for roughly one third of all students. At both undergraduate and postgraduate level, SoM students study on a variety of generalist and specialist degree programmes. All undergraduate degree programmes in the Faculty are three years in duration with an optional professional training year between the second and final year although few students in SoL take up this opportunity. All full time postgraduate programmes in this study are one year in duration. Across the Faculty, there are 129 academic staff, roughly one quarter of which work in SoL. Both schools have a broadly similar proportion of academic staff at professor, reader, senior lecturer, lecturer and tutor grades. Table 2 below gives summary details of the populations and response rates for different groups as well as the sample overall. 
Table 2. Population and sample characteristics

\begin{tabular}{|l|c|c|c|}
\hline Group & Population & Responses & $\begin{array}{l}\text { Response } \\
\text { Rate }\end{array}$ \\
\hline (1) Students & 2625 & 1197 & $46 \%$ \\
\hline Whole Faculty & 569 & 255 & $45 \%$ \\
\hline SoL & 27 & 15 & $56 \%$ \\
\hline SoL Postgraduates & 542 & 240 & $44 \%$ \\
\hline SoL Undergraduates & 253 & 111 & $44 \%$ \\
\hline SoL First Year Undergraduates & 185 & 67 & $36 \%$ \\
\hline SoL Second Year Undergraduates & 104 & 62 & $60 \%$ \\
\hline SoL Final Year Undergraduates & 2056 & 942 & $46 \%$ \\
\hline SoM & 781 & 500 & $64 \%$ \\
\hline SoM Postgraduates & 1275 & 442 & $35 \%$ \\
\hline SoM Undergraduates & 507 & 152 & $30 \%$ \\
\hline SoM First Year Undergraduates & 444 & 160 & $36 \%$ \\
\hline SoM Second Year Undergraduates & 324 & 130 & $40 \%$ \\
\hline SoM Final Year Undergraduates & 129 & 91 & $71 \%$ \\
\hline (2) Academic Staff & 35 & 23 & $66 \%$ \\
\hline Whole Faculty & 94 & 68 & $72 \%$ \\
\hline SoL & \multicolumn{5}{|l}{} \\
\hline SoM &
\end{tabular}

The method of data collection chosen for this study was primarily determined by the ethical regulations of the university in which the Faculty is located. These regulations demand that responses are anonymous and insist that students are made aware of a clear separation between their studies and any involvement in surveys such as this one. In practical terms, this had two implications. First it meant that a paper based survey in, for example, a large lecture was not possible even though "response rates for web surveys are lower than those for paper and pencil surveys" (Sax et al, 2003, p.413). The second effect was that demographic data such as age, ethnicity, gender and, for academic staff, position was not collected. The instrument for the study was administered on-line and all students on taught undergraduate and postgraduate programmes as well as academic staff in the Faculty were invited to participate. The study was conducted in two parts. The first part of the study was for academics and the second was for students. In both cases, invitations to participate 
were e-mailed, reminder e-mails were sent weekly and a weekly notice was placed in the university's virtual learning environment and on the Faculty's staff portal. For both groups the survey was kept open for four weeks.

In total 1197 fully completed responses were received from students giving an overall response rate of $46 \%$ and 91 fully completed responses were received from academic staff giving a response rate of $72 \%$. In terms of the student sample, there is a similar response rate between the two schools although this does mask some significant differences within each population. Response rates were significantly higher, for example, amongst SoL undergraduates compared to SoM undergraduates and the highest response rates amongst all undergraduate students across both schools was amongst students in their final year. The highest response rate was from SoM postgraduate students where almost two in three responded. The response rate was also high amongst SoL postgraduates but this was from a very small population. The response rates were, on the whole, not surprising although the response rate from some groups (such as second year undergraduates) was disappointing. This is, however, consistent with Sax et al's (2003) study which shows that university students are "responding at lower rates than in previous decades" (p. 411) The study does offer significantly higher response rates and sample size than similar studies (for example Koka and Hein, 2003, Miller, 2009, Vardi, 2009, Hyatt, 2005 and Williams, 2005). Nevertheless, the issue of non-response bias still remains and the difficulty for this study is that the usual methods of dealing with non-response bias, for example by comparisons with known values of the population, are not available. The implications of this are two-fold. First, any conclusions drawn from the data must be tentative as 
generalisability may be an issue and, second, findings of this study need to be examined in relation to findings of previous studies in this area.

\section{Findings}

In order to answer the question as to whether academics and students share the same mythology of feedback, it is necessary to first consider the extent to which the different sub-groups in each sample share the same mythology and therefore form a feedback culture as suggested by Macdonald et al (2006). Table 3 presents some basic data from the answers given to the first question about how important feedback is to the student learning experience for both samples. The key issue in measuring the differences between the two groups is the extent to which the observed differences are statistically significant or whether they may have occurred by chance. As with much common practice, for a difference to be viewed as statistically significant, this paper requires a minimum $95 \%$ confidence level (with a p-value of 0.005 or less) that the results have not happened by chance. Also included in this table is the p-value for an ANOVA test that compared the means of each sub-group with the mean of the sample as a whole. In terms of the student sample, at a minimum of $95 \%$ confidence levels, there are no significant statistical differences between how important the sub-groups feel feedback is to their learning compared with the sample as a whole. It is, therefore, reasonable to conclude that, across the Faculty, there is a common student mythology of feedback. The situation with academics is less clear. The p-values suggest that there is a statistically significant difference in how important academics from SoL see feedback compared to the sample as a whole. Given the size of the sample overall, and that SoL academics account for just one quarter of the sample, the practical significance of this difference is, perhaps, more limited and so, as a result, academics will also be treated as a single group. 
Table 3. Summary results by samples and sub-groups

\begin{tabular}{|l|c|c|c|c|}
\hline & Mean & $\begin{array}{c}\text { Standard } \\
\text { Deviation }\end{array}$ & Number & $\begin{array}{c}\text { p-value } \\
\text { compared to } \\
\text { sample as a } \\
\text { whole }\end{array}$ \\
\hline (1) Students & \multicolumn{5}{l|}{} \\
\hline Whole Sample & 3.94 & 0.93 & 1197 & \\
\hline School of Law & 3.98 & 0.96 & 255 & 0.535 \\
\hline School of Management & 3.93 & 0.92 & 942 & 0.804 \\
\hline Undergraduates & 3.98 & 0.94 & 682 & 0.372 \\
\hline Postgraduates & 3.88 & 0.92 & 515 & 0.220 \\
\hline First Year Undergraduates & 4.06 & 0.88 & 263 & 0.056 \\
\hline Second Year Undergraduates & 3.98 & 0.95 & 227 & 0.554 \\
\hline Final Year Undergraduates & 3.88 & 0.99 & 192 & 0.411 \\
\hline (2) Academics & 4.51 & 0.54 & 91 & \\
\hline Whole Sample & 4.18 & 0.40 & 23 & 0.007 \\
\hline School of Law & 4.59 & 0.55 & 68 & 0.361 \\
\hline School of Management &
\end{tabular}

Table 4 presents the results of a series of comparisons between academics and students across the first two elements of the questionnaire; the extent to which feedback is important to the learning experience and the reasons why that view is held. On the basis of an ANOVA test for statistical significance, there would seem to be some significant differences between the two groups; there are clearly held mythologies of feedback but they may not be shared and their intensity may be different. Whilst there is no real difference in how academics and students view the role of feedback in clarifying standards and criteria, across all the other questions the differences are statistically significant. Academics place feedback much more centrally to learning than students and are much more positive about, for example, how feedback explains gaps in knowledge and understanding, promotes self-reflection and self-development and how encouraged and motivated students should feel as a result of the feedback they receive. Only in one area, the impact of feedback on performance, are students significantly more positive than academics. 
Table 4. The mythology of feedback: results for significance of differences between students and academics

\begin{tabular}{|c|c|c|c|c|c|}
\hline \multirow[b]{2}{*}{ Question } & \multicolumn{2}{|c|}{ Students n=1197 } & \multicolumn{2}{|c|}{ Academics n=91 } & \multirow[b]{2}{*}{$\begin{array}{c}p- \\
\text { value }\end{array}$} \\
\hline & Mean & $\begin{array}{l}\text { Standard } \\
\text { Deviation }\end{array}$ & Mean & $\begin{array}{l}\text { Standard } \\
\text { Deviation }\end{array}$ & \\
\hline The importance of feedback & 3.94 & 0.93 & 4.51 & 0.56 & 0.000 \\
\hline $\begin{array}{l}\text { The role of feedback in } \\
\text { improving performance }\end{array}$ & 3.89 & 0.93 & 3.18 & 1.12 & 0.000 \\
\hline $\begin{array}{l}\text { The role of feedback in } \\
\text { clarifying criteria and standards }\end{array}$ & 3.98 & 0.86 & 4.05 & 0.79 & 0.452 \\
\hline $\begin{array}{l}\text { The role of feedback in } \\
\text { explaining gaps in knowledge } \\
\text { and understanding }\end{array}$ & 3.61 & 0.99 & 3.95 & 0.86 & 0.001 \\
\hline $\begin{array}{l}\text { The role of feedback in directing } \\
\text { students to appropriate study } \\
\text { practices }\end{array}$ & 3.41 & 0.94 & 3.64 & 0.90 & 0.024 \\
\hline $\begin{array}{l}\text { The role of feedback in } \\
\text { identifying the gap between } \\
\text { current and hoped for } \\
\text { performance }\end{array}$ & 3.43 & 1.02 & 4.03 & 0.78 & 0.000 \\
\hline $\begin{array}{l}\text { The role of feedback in helping } \\
\text { self-assessment and self- } \\
\text { correction }\end{array}$ & 3.32 & 1.04 & 3.54 & 0.88 & 0.050 \\
\hline $\begin{array}{l}\text { The role of feedback in } \\
\text { promoting self-reflection and } \\
\text { self-development }\end{array}$ & 3.69 & 0.88 & 4.18 & 0.88 & 0.000 \\
\hline $\begin{array}{l}\text { The role of feedback in } \\
\text { motivating and encouraging } \\
\text { students }\end{array}$ & 3.39 & 0.98 & 3.85 & 0.87 & 0.000 \\
\hline
\end{tabular}

Having established that there are differences between academics and students in the Faculty in their mythologies of feedback, the paper now turns to the second research question and the extent to which these different feedback cultures have created dissonance. Table 5 presents the data from the study in the same format and using the same procedures as previously. This evidence shows, overwhelmingly, that there is significant dissonance as the two groups in the study perceive and interpret the same feedback events in very different ways. Only in terms of the usefulness of verbal feedback is there any significant statistical similarity between the two groups and across the other questions the differences in response between academics and students are statistically significant. Students perceive that they receive feedback 
much less frequently than academics perceive that they give feedback, students view the form that they receive feedback in a much less multi-dimensional way than academics and students view marks from, and written comments on, assessed work as being more critical to their learning experience than academics.

Table 5. Dissonance: results for significance of differences between students and academics

\begin{tabular}{|l|c|c|c|c|c|}
\hline & \multicolumn{2}{|c|}{ Students n=1197 } & \multicolumn{2}{c|}{ Academics n=91 } & $\begin{array}{c}\text { Standard } \\
\text { Deviation }\end{array}$ \\
\hline Meastion & Mean & $\begin{array}{c}\text { Standard } \\
\text { Deviation }\end{array}$ & $\begin{array}{c}\boldsymbol{p} \text { - } \\
\text { value }\end{array}$ \\
\hline $\begin{array}{l}\text { Feedback happens frequently, } \\
\text { not just on assessed work }\end{array}$ & 2.34 & 1.05 & 4.15 & 0.81 & 0.000 \\
\hline $\begin{array}{l}\text { Feedback happens when } \\
\text { students and academics meet }\end{array}$ & 2.46 & 1.11 & 3.92 & 0.84 & 0.000 \\
\hline $\begin{array}{l}\text { Feedback happens in written } \\
\text { and non-written forms }\end{array}$ & 2.82 & 1.08 & 4.33 & 0.66 & 0.000 \\
\hline $\begin{array}{l}\text { Verbal feedback is a useful } \\
\text { supplement }\end{array}$ & 3.88 & 0.85 & 4.05 & 0.94 & 0.068 \\
\hline $\begin{array}{l}\text { The most important feedback is } \\
\text { a mark }\end{array}$ & 3.24 & 1.16 & 2.18 & 0.99 & 0.000 \\
\hline $\begin{array}{l}\text { The most useful feedback is } \\
\text { written feedback }\end{array}$ & 3.62 & 0.99 & 2.67 & 1.06 & 0.000 \\
\hline
\end{tabular}

The paper now turns to discuss the implications of this data.

\section{Discussion and Findings}

The first point of discussion is the extent to which the evidence presented represents two different mythologies of feedback or different degrees of attachment to the same mythology. Theoretically, this discussion would probably suggest that there is a grey area between mythologies where it is not absolutely clear where one ends and another begins. This lack of absolute clarity is probably inevitable from any discussion of mythologies in a social process context. Practically, however, the issues are more clear-cut. Whilst both academics and students share the same view that feedback is important in clarifying criteria and standards, they share little else. Most importantly, perhaps, academics view feedback as being much more important as a mechanism for, 
and contributor to, learning than students do and see it as much more powerful in improving performance and changing behaviour than those whom the feedback is intended to help. Whether all this represents separate mythologies or different degrees of attachment is probably a moot point as what is clear is that dissonance is present as academics and students offer very different perspectives on the same feedback events examined.

Macdonald et al (2006) suggest that the primary cause of dissonance is where expectations are not met and so the obvious question to ask is: Why do academics and students have such different expectations of feedback? The answer to this question probably lies in three areas; the behaviour of students, the behaviour of academics and the environment in which they interact. Answering this question is, in any case, beyond the scope of this paper save to point out that much of the literature discussed earlier suggests a number of different causes of the expectations gap in feedback such as the massification of higher education and resultant large classes, increasing student diversity, modularisation and semesterisation and a general failure within and outside higher education to adequately prepare students for the demands of undergraduate and postgraduate study. Whilst the causes of this gap are multi-dimensional, opaque and complex, the outcomes are likely to be disappointing for all concerned. For academics the disappointment may well be in efforts going unrecognised and opportunities foregone; effort put into feedback that is not focused on assessment, despite the investment of time and resources, is simply not seen as feedback by students. For institutions, the disappointments are likely to be in returns on improvements to the technical processes of feedback that are frequently not reflected in, for example, National Student Survey results as is the case in the Faculty under discussion in this 
paper. For students, the disappointment may be in their learning experience that may be built on how academics think they should learn rather than on how they do learn.

So, how do students learn? The traditional model, particularly when learning is viewed through a technical rather than a social lens, suggests that it is an iterative process whereby a student's learning is improved as they receive, understand and act on feedback given throughout their period of study. In this framework, learning has both a content dimension (what is learned) and a skills dimension (how it is learned). This study suggests that this approach to understanding the student learning experience, accepted and acknowledged as it is in much of the general and discipline specific literature, is not an accurate reflection of what is actually happening. Students cannot learn from feedback if they do not recognise that they are receiving feedback or if they are only interested in the marks they receive on assessed work. This is probably the most important area for future research raised by this study; if learning is not happening through the formal feedback process, how is it happening and how effective are these other processes?

The dissonance between staff and students identified in this study is, of course, only a problem if it remains unaddressed and ignored; if the identification of dissonance becomes the starting point for the creation of a new mythology of feedback which is shared by staff and students then it can have a positive dimension. Given the relationship between the two groups it is much more likely that a common understanding will begin with academics reviewing their own beliefs, behaviours and practices. For example, in undergraduate and postgraduate degree schemes that are modular and, therefore, contain a series of stand-alone components with clear 
boundaries, can feedback in an early module be used to improve performance in later modules? Similarly, given the growth of ever more detailed marking schemes for assessments, does feedback become something which is too specific to a single episode of assessment rather than generalisable to the learning experience as a whole. Mutch (2003) views improvements to feedback as issues of programme and module design more than anything else which begins with the way in which students are inducted into their studies and made aware of the challenges and opportunities of undergraduate and postgraduate study. As with any social process, dealing with issues of dissonance is a complex matter and rarely quick or easy. Whilst dealing with dissonance goes beyond the scope of this paper, future research in the area may wish to consider how dissonance can be reduced through, for example, interventions in induction and orientation programmes, the design of programmes of study and assessment strategies.

Overall, this paper has identified significant dissonance between academics and students in their perceptions of how important and useful feedback is. How significant are these findings in a wider sense? The obvious limitation of the study is that it concerned students in just one faculty in one UK university and so there are inevitably questions to be asked about generalisability. There are four factors that suggest that the implications of the study have a wider reach than the single context in which they are set. First, the evidence presented is clear and consistent and offers a coherent picture of the mythology of feedback amongst the two groups under discussion. Second, the evidence is built across two schools in two different disciplines with a large enough sample size in both groups for the data to have a significant weight attached to it. Third, both SoL and SoM are typical of law and 
business/management schools in this part of the higher education sector; there is

nothing about the two examples in terms of programmes, staff profile or student

profile which makes them atypical. Finally, the evidence is both reflective and

supportive of much of the literature from both a generalist and a discipline specific

perspective. Therefore, the contention is that the findings of the paper have a degree

of generalisability, certainly to other schools of law and management, but that further

research is necessary to see if they also apply to other disciplines.

\section{References}

Barrow, M. (2006) Assessment and student transformation: linking character and intellect in Studies in Higher Education, volume 31, number 3, pp.357-372.

Bloxham, S. and West, A. (2007) Learning to write in higher education: students' perceptions of an intervention in developing understanding of assessment criteria in Teaching in Higher Education, volume 12, number 1, pp77-89.

Bone, A. (1999) Ensuring Successful Assessment, National Centre for Legal Education, University of Warwick, UK.

Bone, A. (2006) The Impact of Formative Assessment on Student Learning, UK Centre for Legal Education, Higher Education Academy.

Burke, D. (2009) Strategies for using feedback students bring to higher education in Assessment and Evaluation in Higher Education, volume 24, number 1, pp4150.

Carless, D. (2006) Differing perceptions in the feedback process in Studies in Higher Education, volume 31, number 2, pp219-233.

Case, S. (2007) Reconfiguring and realigning the assessment feedback process for an undergraduate criminology degree in Assessment and Evaluation in Higher Education, volume 32, number 3, pp285-299.

Cowan, J. (2004) Improving student learning through departmental student feedback self-studies, Learning and Teaching Support Network position paper.

Crisp, B.R. (2007) Is it worth the effort? How feedback influences students' subsequent submission of assessable work in Assessment and Evaluation in Higher Education, volume 32, number 5, pp571-581.

Eden, C. (1992) Strategy development as a social process in Journal of Management Studies, volume 29, number 6, pp799-811.

Espeland, W.N. and Stevens, M.L. (1998) Commensuration as a social process in Annual Review of Sociology, volume 24, pp.313-347.

Gibbs, G. and Simpson, C. (2004-5) Conditions under which assessment supports student learning in Learning and Teaching in Higher Education, issue 1, pp331.

Glover, C. (2004) Report of research carried out at Sheffield Hallam University for the Formative, Assessment in Science Teaching project, FAST, Higher Education Academy.

Handley, K., Price, M. and Millar, J. (2009) Engaging Students with Assessment Feedback, FDTL5 Project Report, Higher Education Academy. 
Holmes, K. and Papageorgiou, G. (2009) 'Good, bad and insufficient' Students expectations, perceptions and uses of feedback in Journal of Hospitality, Leisure, Sport and Tourism Education, volume 8, number 1, pp85-96.

Hounsell, D., McCune, V., Hounsell, J. and Litjens, J. (2006) Investigating and Enhancing Guidance and Feedback to Undergraduate Students, $3{ }^{\text {rd }}$ Biennial Northumbria/EARL SIG Assessment Conference.

Hyatt, D.F. (2005) 'Yes, a very good point!' A critical genre analysis of a corpus of feedback commentaries on Master of Education assignments in Teaching in Higher Education, volume 10, number 3, pp339-353.

Hyland, F. and Hyland, K. (2001) Sugaring the pill: Praise and criticism in written feedback in Journal of Second Language Writing, volume 10, pp185-212.

Koka, A. and Hein, V. (2003) Perceptions of teacher's feedback and learning environment as predictors of intrinsic motivation in physical education in Psychology of Sport and Exercise, volume 4, pp333-346.

Macdonald, I., Burke, C. and Stewart, K. (2006) Systems Leadership: Creating positive organisations, Gower Publishing Ltd, Surrey, UK.

Maitlis, S. (2005) The social processes of organisational sensemaking in Academy of Management Journal, volume 48, number 1, pp.21-49.

Miller, N. (2004) Alternative forms of formative and summative assessment in the Handbook for Economics Lecturers, Higher Education Academy.

Miller, T. (2009) Formative Computer Based Assessment in higher education: the effectiveness of feedback in supporting student learning in Assessment and Evaluation in Higher Education, volume 34, number 2, pp181-192.

Moriarty, J. and Rajapillai, V. (2009) How can teaching help with assessment? Enhancing peer feedback through blogging on creative writing, Beyond the Essay: Assessment in English Literature and Creative Writing Conference, University of Brighton.

Mutch, A. (2003) Exploring the practice of feedback to students in Active Learning in Higher Education, volume 4, number 24, pp24-38.

Nicol, D.J. and Macfarlane-Dick, D. (2006) Formative assessment and self-regulated learning: a model and seven principles of good feedback practice in Studies in Higher Education, volume 31, number 2, pp199-218.

Orrell, J. (2006) Feedback on Learning Achievement: rhetoric and reality in Teaching in Higher Education, volume 11, number 4, pp441-456.

Parry, K.W. (1998) Grounded Theory and Social Process: A new direction for leadership research in Leadership Quarterly, volume 9, number 1, pp.85-105.

Parikh, A., McReelis, K. and Hodges, B. (2001) Student feedback in problem based learning: a survey of 103 final year students across five Ontario medical schools in Medical Education, volume 35, pp632-636.

Race, P. (March 2007) Designing Assessment to Improve Physical Sciences Learning, Physical Sciences Centre, Higher Education Academy.

Sampson, R., Morenoff, J.D. and Gannon-Rowley, T. (2002) Assessing 'neighbourhood effects': Social processes and new directions in research in Annual Review of Sociology, volume 28, pp.443-478.

Sax, L.J., Gilmartin, S.K. and Bryant, A.N. (2003) Assessing response rates and nonresponse bias in web and paper surveys in Research in Higher Education, volume 44, number 4, pp409-432.

Vardi, I. (2009) The relationship between feedback and change in tertiary student writing in the disciplines in International Journal of Teaching and Learning in Higher Education, volume 20, number 3, pp350-361. 
Weaver, M.R. (2006) Do students value feedback? Student perceptions of tutors' written responses in Assessment and Evaluation in Higher Education, volume 31, number 3, pp379-394.

Williams, K. (2005) Lecturer and first year student (mis)understandings of assessment task verbs: 'Mind the Gap in Teaching in Higher Education, volume 10, number 2, pp157-173.

Woolf, H. (2004) Assessment criteria: Reflections on current practices in Assessment and Evaluation in Higher Education, volume 29, number 4, pp479-493.

Zydziunaite, V. and Lepaite, D. (2009) Aspects of social processes within a business organisation for a positive development of organisational behaviour in Current Issues in Business and Law, volume 4, pp.103-121. 